\title{
Online Discussion Support System with Facilitation Function
}

\author{
Chihiro Sasaki $^{1}$, Tatsuya Oyama ${ }^{2}$, Shin Kajihara ${ }^{4}$ \\ Graduate School of Science and Engineering \\ Saga University \\ Saga, Japan
}

\author{
Chika Oshima $^{3}$, Koichi Nakayama ${ }^{5}$ \\ Faculty of Science and Engineering \\ Saga University \\ Saga, Japan
}

\begin{abstract}
In this paper, we present a discussion board system (DBS) with a facilitator function that we developed for the purpose of facilitating discussions that require decision-making that incorporates diverse values and opinions. Its function is to constantly extract nouns from the utterances of discussion participants and display them on the DBS on each participant's personal computer. Items to be decided in the discussion are displayed together with a frame (called a "box"), and each participant puts the displayed keywords in the box according to their own opinions and intentions. No other participant can see what the individual is doing. The color of any keyword that all participants put in the same box changes to green. Furthermore, comments are automatically presented based on the time when each participant last spoke and the time when the keyword was moved. This is intended to encourage participants who appear to be less involved to join the discussion. Experiments with the DBS suggested that it might be possible to capture the will of participants who disagree but do not speak. However, it was also deemed necessary to post comments that encourage participants to express their intentions independently, and to have a mechanism that can link the motivated manifestation of intentions to appropriate actions.
\end{abstract}

Keywords-Discussion board system; decision-making; facilitation function; diverse values and opinions

\section{INTRODUCTION}

In recent years, the realization of "diversity management" has become an issue for Japanese companies. The diverse perspectives shared by employees of different genders, nationalities, and backgrounds are thought to enhance corporate competitiveness. However, discussions that touch upon diverse values are easily confused, and participants in the discussions can easily lose sight of their goals and the current situation. Participants may forget what they have and have not yet discussed, or may not be able to reach a conclusion in time due to conversation loops, derailments, and incorrect time allocation. Furthermore, in situations where the hierarchical relationships [1] among individuals is clear, such as meetings within a company, the "peer pressure" [2] [3] that must be synchronized with the remarks of superiors hinders participation. This is also a factor that causes participants to hesitate to express various perspectives. The existence of a facilitator [3] is thought to have a certain effect on reducing the peer pressure among participants and appropriately advancing discussions based on various viewpoints. Mori [3] organizes the roles of facilitators into four tasks. The first is "designing the process." The facilitator clearly sets the goals of the discussion [4] based on the objectives and deliverables and logically and psychologically designs the optimal process toward the goals. The second is "controlling the process." The facilitator controls the process of discussion and prevents emotional conflicts from interfering with the discussion. While maintaining neutrality, the facilitator encourages other participants to speak so that a small number of hardline opinions and peer pressure do not lead to a conclusion. The facilitator assumes a referee position for the participants and provides a psychological safety zone for them by approving and encouraging the expression of different opinions as a necessary act. The third is to "organize and inspire discussions." The facilitator inspires participation in the discussion by asking the participants questions, summarizing and paraphrasing the opinions they present, and organizing the story so that the overall understanding is deepened. The fourth is to "form an agreement." The facilitator elicits opinions from all participants as much as possible and gives a sense of conviction that the discussion was properly and adequately conducted. Identifying the right time, the facilitator encourages participants to reach conclusions and encourage consensus building.

Despite their benefits, competent facilitators are not always present in discussions and cannot play these roles. Therefore, based on the role of these facilitators, we aimed to develop an artificial intelligence (AI) facilitator capable of autonomously facilitating discussions. In this paper, as the first step toward the AI facilitator, we developed a discussion board system (DBS) that realizes some of the facilitator's functions [5][6]. We verify whether the support of the DBS system is effective in reducing peer pressure and providing a psychological safety zone for group discussions. This study does not cover discussions aimed at generating many ideas, such as brainstorming sessions. Similarly, it excludes guided discussions where it is best for a highly specialized person to take a leadership role and decide everything. What we envision is a discussion aimed at forming a collective consensus on a given set of issues and drawing conclusions after considering various opinions.

Related research will be described in the next section. Section III gives an overview of the DBS. Section IV describes the system design based on the facilitator function [3]. In Section V, we outline our experiment with the discussion using DBS ver. 1.0, which implements facilitator Functions 1 and 2. We analyze the differences between the conclusions that the participants perceive as "agreed" and the 
opinions left on each participant's DBS [5]. In Section VI, we outline our experiment with discussions using DBS ver. 2.0, which implements facilitator Functions 1-4. Analyses were conducted concerning whether the comments displayed by the DBS were useful for facilitating discussions. Furthermore, by considering the intentions of the participants in the discussion from the viewpoint of peer pressure, we consider the role required for AI facilitators in the future. The paper is summarized in Section VII.

\section{RELATED RESEARCH}

To date, many discussion support systems have shared their screens among all participants. The MERMAID provides a way for people remote from one another to share information in multimedia forms such as video images, voice, text, graphics, still images, and hand-drawn figures [7]. However, to maintain the consistency of the displayed contents among the participants, one must acquire the right to operate the shared screen. In recent years, it has become possible for multiple people to share a document, for example "Google docs," retrieve and quote discussions from previous meetings [8], evaluate participants' contributions to discussions and visualize these views to the participants [9], and indicate participants' degree of self-confidence using a six-point scale in order to generate clues regarding the possibilities for compromise [10]. In the system proposed in this paper, to secure a psychological safety zone, the space for displaying the participants' opinions is not disclosed to other participants during the discussion.

There are some existing systems for new idea-generation support. Gungen [11] was developed to perform the distributed KJ method. Combinator [12] supports a designer's new idea creation by combining familiar ideas. Nishimoto [13] developed a system that structurally visualizes keywords automatically extracted from the comments of each participant during a discussion based on a word's appearance rate and reproduction efficiency. Idea expander [14] and SWISS [15] are idea-generation support systems that present images searched for based on the participants' text chats [14] or utterances [15]. In contrast, this paper focuses on discussions aimed at forming group consensus on tasks and drawing conclusions.

In the systems for group decision-making meetings, INGA [16] is a system that automatically searches for and presents electronic data from meeting materials that are highly relevant to discussions based on keywords obtained from voice input. Ohira [17] aimed to evaluate participants' ability to discuss and improve motivation through a form of discussion called "gamification discussion." Shimizu [18] presented a system in which participants can vote on ideas during a discussion. Discussion Media [19] is a system in which each participant can arbitrarily input their stance regarding the presentation and any arguments with other participants using a button device. The system proposed in this paper also has a function for categorizing keywords into boxes, but these are not published to other participants during the discussion.

COLLAGREE [20] is an open web-based forum system that has facilitator support functions and was deployed during an internet-based town meeting in Nagoya, Japan as a city project led by its mayor. D-Agree [21] analyzes the words written on a bulletin board and automatically facilitates the discussion. The system proposed in this paper is intended for discussions among small face-to-face groups aimed at decision-making. The system also has a facilitation function that presents comments based on the time while each participant is silent and/or a history of moving words in a display created by the participant.

\section{DISCUSSION BOARD SYSTEM}

We developed DBS ver. 1.0 [5] (see Fig. 1) and ver. 2.0 (see Fig. 2) to promote good discussions. A "good discussion" in this study is defined as below:

- In the shortest time, draw conclusions related to all items that need to be considered.

- The consensus of more attendees is a better decision than one with a lower level of consensus.

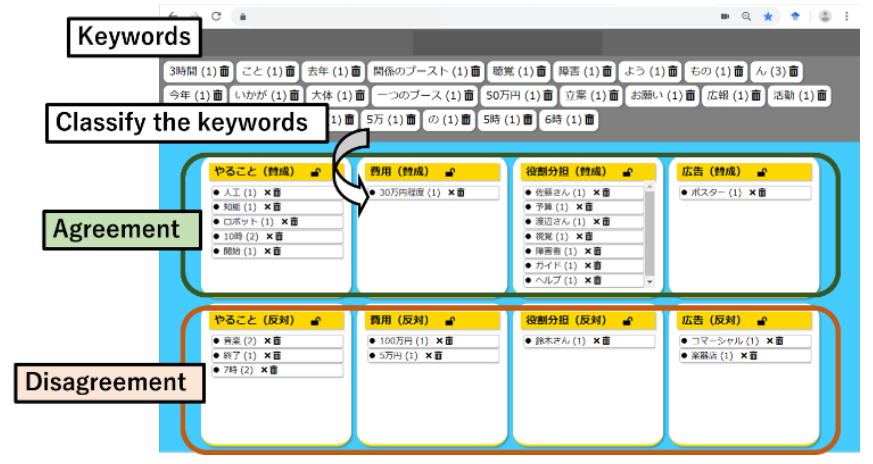

Fig. 1. DBS ver. 1.0.

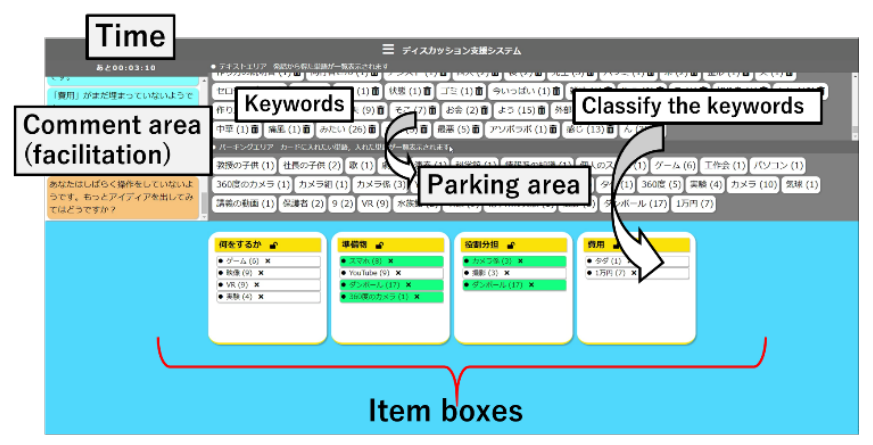

Fig. 2. DBS ver. 2.0.

All attendees participate in the discussion. Even if they make no remarks, they will think of possible solutions to the problem and will ultimately be called upon to express their willingness / agreement with the decisions made.

\section{A. Overview}

The DBS displays the "boxes" of the categories to be decided in the discussion on each participant's screen. For example, in the case of the theme of "a gift," the terms "flowers," "fruits," "handkerchiefs," “accessories," etc. are displayed as category boxes on the DBS display.

The DBS uses speech recognition to extract nouns (hereinafter referred to as "keywords") from discussions and 
display them. Each participant can express their opinion concerning whether or not words are appropriate for the category by putting the keywords in the box using the "drag and drop" operation according to their opinion and intention, because each participant's screen is intentionally made invisible to other participants. For example, keywords such as apples and grapes are lined up on the display. If one participant puts "apples" in the "fruit" box, he is indicating the decision "if the gift is a fruit, apples are good."

The DBS also presents boosting comments on the screen and encourages participants who have not spoken or manipulated the screen for a certain period of time to participate in the discussion with comments.

After the discussion is over, the number of keywords in the box is totaled. It is also possible to share the results among participants without revealing information about who moved which keyword to the box and when.

If all participants put the same keyword in one category box, the DBS will change the color of that word to green. Participants then know that other participants entered the same keyword in the category box.

The following sections detail the four functions of the facilitator, as realized by the DBS.

\section{B. Function 1: Designing the Process}

The DBS clarifies items to be discussed (goals), what has already been discussed, and what has not yet been discussed (current position). This feature helps participants reach the necessary and sufficient conclusions in time.

- Set a box on the terminal screen for each item to be decided (implemented in DBS ver. 1.0, 2.0).

- Show how many minutes are left to reach a conclusion (implemented in DBS ver. 2.0).

- Show the status of the box by commenting to all participants (implemented in DBS ver. 2.0).

Fig. 3 shows an algorithm for displaying comments (A) to (C). It is executed at regular intervals (every 8 minutes in Experiment 2) and displayed to all participants at the same time.

(A) It seems that " $x$ (item name of the corresponding box)" is not filled yet.

(B) “ $x$ ” seems to vary.

(C) It seems that " $x$ " is just around the corner.

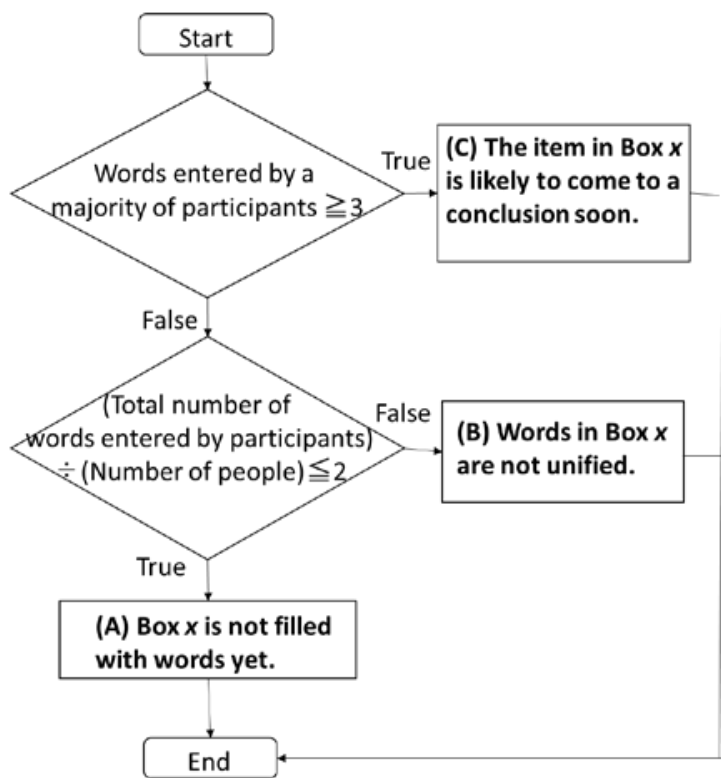

Fig. 3. An Algorithm for Displaying Comments A-C.

\section{Function 2: Controlling the Process}

The DBS provides a psychological safety zone to control the process of discussion and prevent emotional conflicts from interfering with it. Each participant moves the keywords to the box according to their own opinion and intention, without being seen by others. It is hoped that the true intentions of each participant will therefore be expressed. After the discussion of each item is concluded, participants press the "lock" button to indicate the discussion's end. After the discussion is over, the system can aggregate the keywords in the boxes and share them among the participants. At that time, it is not clear who moved each keyword into the box. Therefore, the box area is a "semi-personal space" that can be shared by all participants while they easily express their personal opinions.

\section{Function 3: Organize and Inspire Discussion}

The DBS will display comments to encourage participants who have stopped speaking or moving keywords for a while to stimulate discussion. This function was implemented in DBS ver. 2.0. Fig. 4 shows an algorithm that is executed at regular intervals (every 8 minutes in Experiment 2) among the comments displayed to the relevant participants.

(D) (If there is only one participant who puts a keyword different from the others in the box) You put "keyword y" in "box x.” Would you like to give us your opinion on “y”? 


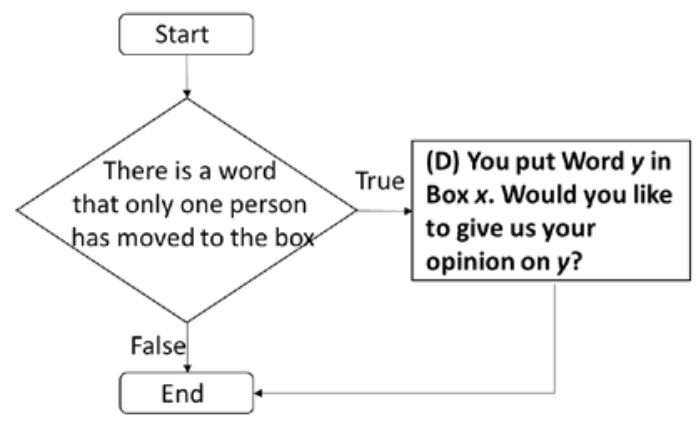

Fig. 4. An Algorithm for Displaying Comments D.

Fig. 5 shows an algorithm that is always running while the system is running and is presented to the relevant participants.

(E) You don't seem to have spoken for a while. Would you like to give us an opinion?

(F) You don't seem to have been operating for a while. Could you give me more ideas?

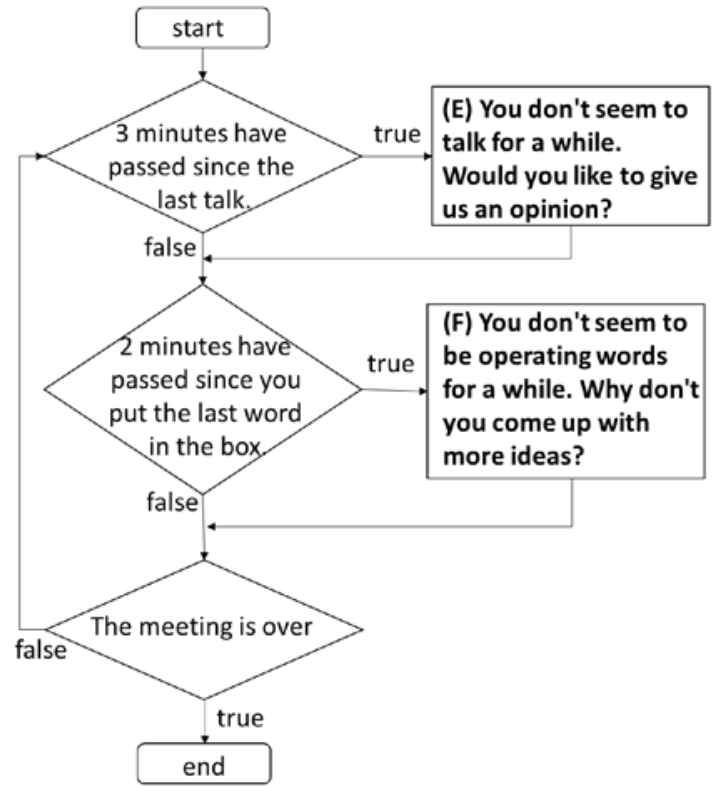

Fig. 5. An Algorithm for Displaying Comments E and F.

\section{E. Function 4: Form an Agreement}

When all participants enter the same keyword in the same box, the keyword changes to green (call this function a "deliverable display") (implemented in DBS ver. 2.0). By turning green, participants know that all participants are likely to agree, and it is an opportunity to settle the discussion.

The "parking area" is a place to temporarily store keywords for which it is difficult to decide whether or not to put into a box (implemented in DBS ver. 2.0). The words in the parking area are disclosed to other participants. This function avoids the DBS treating words with the same intention as different words. For example, "Venice" and "Venetia" have exactly the same meaning, but they are recognized as different words in the DBS. However, if "Venice" is in the parking area, most of the participants will move "Venice," not "Venetia," into the box, when they agree with this word. This function is also useful for the deliverable display function.

\section{F. Extracting and Displaying Keywords}

Each participant's voice is recognized by each personal computer, and the extracted keywords of all participants are displayed on all terminals at almost the same time [5][6]. As shown in Fig. 6, utterances are always recognized by the speech recognition capability of the "Web Speech API." The recognized characters are parsed using the Japanese morphological analysis engine "kuromoji.js" or the named entity extraction API (selectable). "Keywords" are extracted from the word group after the parsing is completed. Suffixes and particles to be adnominal are grouped as the same keyword. Keywords are sent to the server and registered.

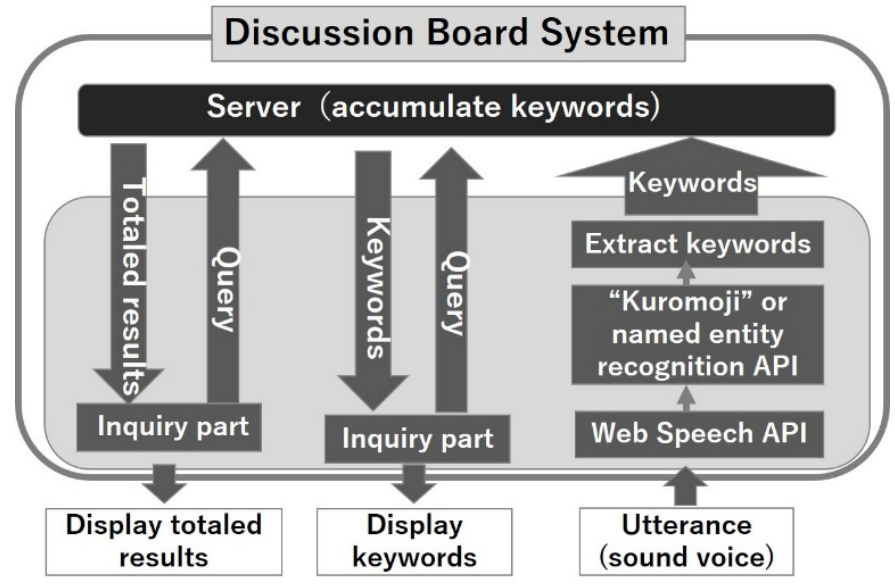

Fig. 6. System Flow.

At the same time that the voice recognition starts, the application inquires at regular intervals whether a new keyword is registered on the server. Keywords extracted from the utterances of all participants are targeted. If there is a new keyword, it will be acquired and displayed on the screen. The time of the inquiry server is recorded, and then only the keywords registered after the recorded time are acquired and the last inquiry time is updated. The inquiry interval can easily be changed by setting the DBS, and four types, of $0.5 / 1 / 2 / 3$ seconds, are prepared, where the initial state is 1 second. In other words, the maximum set inquiry interval is delayed from the time the keyword is registered until the screen is displayed.

\section{EXPERIMENT 1}

\section{A. Purpose}

DBS ver. 1.0 (Fig. 1) was used for the discussion, and the following two points were considered. (1) The effect of the box and (2) the usefulness of a semi-personal space. Regarding (2), we aimed to verify our findings based on the differences between individuals' and overall decision-making, as estimated from the keywords left in the box.

\section{B. Method}

The participants in the experiment were four first-year male graduate students (participants A-D). Each participant was given a laptop computer with the DBS. 
Of the four participants, two entered separate soundproofed rooms, while the other two sat in the opposite corners of a room approximately 50 square meters in area. Their discussion was held online using the Internet calling system Skype. No images were transmitted, only each participant's voice.

The agenda set for the four participants was "Think about how to entertain children and their parents at a fun kindergarten event.”

The terms of the discussion were summarized on a piece of paper and passed to the participants: The performers were the four participants in this experiment / Days before the fun event / Performance time / Location / Room situation (fictitious photo with mini stage and speakers) / Kindergarten age / Gender / Number of children and parents / What to expect from the kindergarten / Background of the party (PR for becoming a kindergarten that you want to attend) / No budget.

The items to be decided during the discussion were specified by the experimenter. These were: 1 . What to do, 2. Preparations, 3. Role sharing, and 4. Cost. Two types of boxes were provided for each item, "agree” and "disagree.” For example, for the item "cost," if the participant agreed with "about 300,000 yen," he moved the keyword "300,000 yen” to the box marked "cost-agree." If not, it is moved to the box "cost-disagree." Keywords can also be moved to another box or deleted. A total of eight boxes were prepared. Prior to the experiment, the experimenter registered eight boxes in each computer's system. Participants were instructed to decide on these four items within a specific time.

It was requested that the movement of keywords to the box should be decided by the participants' own intentions and opinions, rather than taking direction from the group. We instructed all participants to decide these four items (agreement) within 40 minutes. The screen recording software "Filmora Scrn" was used to record the screens of each participant, in addition to their faces and utterances. However, due to a malfunction of the experimental equipment, it was not possible to capture the video for Participant C's screen.

\section{Questionnaire Survey}

After the experiment, the four participants answered Questionnaire 1 while seated at the same table. At the time of the experiment, the "item box" element was called a "category."

1) Questionnaire 1

Question 1-1: What was the conclusion of the discussion (concluded / not reached)? Please write the final conclusions of your perceived discussion by category (what to do / preparation / separation / costs). Do not consult with the other participants, and answer using your own words. If there are any categories for which you have not yet reached the end of the discussion, please write down the conclusions that you think are the most likely at this time. If there was not one conclusion, please describe all conclusions reached.

Question 1-2: What did you think and judge when moving keywords to the categories? Fill in as much detail as possible about the criteria for sorting and what you were thinking when moving the words.

Question 1-3: How did the discussion proceed?

- Was the discussion lively?

- Were participants' opinions easy to agree with?

- Do you feel that you reached the conclusion smoothly?

Next, the four participants responded to Questionnaire 2 while looking at the results of the totals for all eight items and their responses to Questionnaire 1.

\section{2) Questionnaire 2}

Please answer the following questions about Questionnaire 1, which you completed earlier, while looking at the display showing all of the results from all participants.

Question 2-1: What was the biggest difference between the final conclusion you reported in Questionnaire 1 and the actual results from all participants?

Question 2-2: Remember the flow of the discussion. Were there any times where your intentions and opinions were different from the opinion and story flow of the entire group? What did you think about that?

Question 2-3: Look at the tally results on the display. Are there any of your conclusions in Question 1 from Questionnaire 1 that you think should be corrected? If so, what are they?

\section{Results}

1) Participants' commenting behaviors: The following tends were observed from the analysis of utterances. The basic form of the discussion was that multiple opinions were presented in response to the questioning remarks (for example, "Is there anything other than the play?" "What are the preparations?"), and the most-supported remarks were expanded to the next discussion. When there were concerns or points to be noted regarding the remarks, the behavior was seen in which the topic was interrupted, rather than expressing dissenting opinions. Participants sometimes suddenly made remarks that were not linked to those immediately before. For example, immediately after "cleaning up time is about 5 minutes," They switched to the next discussion with "then, preparations." In the latter half of the discussion, participants began to speak with an emphasis on nouns.

2) Keywords left in the box: Table I shows the keywords that finally remained in the box and the aggregated results. There were almost no differences in the number of keywords between items other than "cost" and among the participants. However, all four participants put only five keywords in the same box, four of which were in "role division." In "what to do," two people put "magic" and another two put "magic tricks.” These two keywords are considered synonymous, so it can be said that there was a total of six common keywords. Participants B and C left the "curtain" in the "preparation (agreement)," while A put it in the "preparation (opposite).” Analyzing the utterances, Participants A, B, and C recognized 
that they would use the kindergarten curtains. However, B and C put the keyword in "agree," in the sense of "preparing the curtain," while A put it in "opposite," in the sense that "the curtain is at the kindergarten, so no preparation is necessary."

TABLE I. KEYWORDS LEFT IN EACH BOX

\begin{tabular}{|c|c|c|c|}
\hline category & participant & remaining keywords & totalization \\
\hline \multirow{4}{*}{ what to do (agree) } & A & $\begin{array}{l}\text { Momotaro, Oni(devil), workshop, magic (in } \\
\text { English), juggling, Talk (free conversation), } \\
\text { lecture, background music }\end{array}$ & \multirow{4}{*}{$\begin{array}{l}\text { one using cards(3), magic (in English)(2), magic (in } \\
\text { Japanese)(2), juggling(3),participation(2), workshop (2), } \\
\text { simplification, Momotaro, Oni, lecture, background } \\
\text { music, Talk, participation, communication }\end{array}$} \\
\hline & B & one using cards, magic, simplification & \\
\hline & $\mathrm{C}$ & $\begin{array}{l}\text { one using cards, magic (in English), juggling, } \\
\text { magic (in Japanese) }\end{array}$ & \\
\hline & $\mathrm{D}$ & $\begin{array}{l}\text { participation, workshop, one using cards, juggling, } \\
\text { communication }\end{array}$ & \\
\hline \multirow{4}{*}{$\begin{array}{l}\text { what to do } \\
\text { (disagree) }\end{array}$} & A & arrangement of effects, projection mapping & \multirow{4}{*}{$\begin{array}{l}\text { Momotaro(2) } \\
\text { arrangement of effects, projection mapping(2) }\end{array}$} \\
\hline & B & Momotaro, projekution mapping & \\
\hline & $\mathrm{C}$ & Momotaro & \\
\hline & $\mathrm{D}$ & -- & \\
\hline \multirow{4}{*}{ preparation (agree) } & A & $\begin{array}{l}\text { banana, cards, costume for a behind-the-scenes } \\
\text { supporter }\end{array}$ & \multirow{4}{*}{$\begin{array}{l}\text { handkerchief(2), banana(4), cards(3), curtains(2), } \\
\text { costume for behind-the-scenes supporter(2), } \\
\text { cloth of a dog, low-cost, beanbags, bowling pins }\end{array}$} \\
\hline & B & $\begin{array}{l}\text { handkerchief, low-cost, banana, cards, curtains, } \\
\text { beanbags }\end{array}$ & \\
\hline & $\mathrm{C}$ & $\begin{array}{l}\text { handkerchief, banana, cloth of a dog, cards, } \\
\text { curtains }\end{array}$ & \\
\hline & $\mathrm{D}$ & $\begin{array}{l}\text { banana, teacher, cards, beanbags,bowling pins, } \\
\text { costume for a behind-the-scenes supporter }\end{array}$ & \\
\hline \multirow{4}{*}{$\begin{array}{l}\text { preparation } \\
\text { (disagree) }\end{array}$} & A & curtains, spotlight, building clocks, projector & \multirow{4}{*}{$\begin{array}{l}\text { spotlight(2), } 10 \text { pieces, wall, hole, curtains, building } \\
\text { clocks, projector }\end{array}$} \\
\hline & B & 10 pieces, wall, hole & \\
\hline & $\mathrm{C}$ & -- & \\
\hline & $\mathrm{D}$ & spotlight & \\
\hline \multirow{4}{*}{ role sharing (agree) } & A & $\begin{array}{l}\text { assistant, a behind-the-scenes supporter, } \\
\text { moderator, magician }\end{array}$ & \multirow{4}{*}{$\begin{array}{l}\text { assistant(4), a behind-the-scenes(4), moderator(4), } \\
\text { magician(4), background music(2), Neta, juggling, } \\
\text { teacher }\end{array}$} \\
\hline & B & $\begin{array}{l}\text { Neta (a joke material), assistant, a behind-the- } \\
\text { scenes supporter, moderator, juggling, teacher, } \\
\text { background music, magician }\end{array}$ & \\
\hline & $\mathrm{C}$ & $\begin{array}{l}\text { assistant, a behind-the-scenes supporter, } \\
\text { moderator, magician }\end{array}$ & \\
\hline & $\mathrm{D}$ & $\begin{array}{l}\text { assistant, a behind-the-scenes supporter, } \\
\text { moderator,background music, magician }\end{array}$ & \\
\hline \multirow{4}{*}{ costs (agree) } & $\mathrm{A}$ & -- & \multirow{4}{*}{4000 yen (3) } \\
\hline & $\mathrm{B}$ & 4000 yen & \\
\hline & $\mathrm{C}$ & 4000 yen & \\
\hline & $\mathrm{D}$ & 4000 yen & \\
\hline \multirow{4}{*}{ costs (disagree) } & A & 4580 yen & \multirow{4}{*}{$\begin{array}{l}4580 \text { yen (2) } \\
\text { price of a dog }\end{array}$} \\
\hline & B & 4580 yen & \\
\hline & $\mathrm{C}$ & price of a dog & \\
\hline & $\mathrm{D}$ & -- & \\
\hline
\end{tabular}


TABLE II. RESULtS OF QUESTION 1-1.

\begin{tabular}{|c|c|c|c|c|}
\hline Category & Participant & Conclusion & $\begin{array}{l}\text { Final conclusions recognized by } \\
\text { individuals }\end{array}$ & $\begin{array}{l}\text { Difference in number from } \\
\text { words left in the box }\end{array}$ \\
\hline \multirow{4}{*}{ What to do } & A & yes & magic show & Seven words decreased \\
\hline & $\mathrm{B}$ & yes & magic & Two words decreased \\
\hline & $\mathrm{C}$ & yes & magic & Three words decreased \\
\hline & $\mathrm{D}$ & yes & magic, juggling & Four words decreased \\
\hline \multirow{4}{*}{ Preparation } & A & yes & $\begin{array}{l}\text { banana, cloth, cards, ling, } \\
\text { beanbags }\end{array}$ & $\begin{array}{l}\text { One word decreased, three } \\
\text { words increased }\end{array}$ \\
\hline & $\mathrm{B}$ & yes & $\begin{array}{l}\text { handkerchief, cards, ball for } \\
\text { juggling, cloth, banana }\end{array}$ & $\begin{array}{l}\text { Three words decreased, } \\
\text { two words increased }\end{array}$ \\
\hline & $\mathrm{C}$ & yes & $\begin{array}{l}\text { handkerchief, banana, cards, } \\
\text { curtain }\end{array}$ & One word decreased \\
\hline & $\mathrm{D}$ & yes & $\begin{array}{l}\text { banana, beanbags, cards, cloth, } \\
\text { costume for a behind-the-scenes } \\
\text { supporter }\end{array}$ & $\begin{array}{l}\text { Two words decreased, one } \\
\text { word increased }\end{array}$ \\
\hline \multirow{4}{*}{ Separation } & A & yes & $\begin{array}{l}\text { magician, moderator, assistant, a } \\
\text { behind-the-scenes supporter }\end{array}$ & No change \\
\hline & $\mathrm{B}$ & yes & $\begin{array}{l}\text { magician, moderator, assistant, a } \\
\text { behind-the-scenes supporter }\end{array}$ & Four words decreased \\
\hline & $\mathrm{C}$ & yes & $\begin{array}{l}\text { magician, moderator, assistant, a } \\
\text { behind-the-scenes supporter }\end{array}$ & No change \\
\hline & $\mathrm{D}$ & yes & $\begin{array}{l}\text { magician, moderator, assistant, a } \\
\text { behind-the-scenes supporter }\end{array}$ & One word decreased \\
\hline \multirow{4}{*}{ Costs } & A & yes & 4000 yen or less & "4000 yen" remained \\
\hline & $\mathrm{B}$ & yes & about 4000 yen & "4000 yen" remained \\
\hline & $\mathrm{C}$ & yes & 4000 yen & No change \\
\hline & $\mathrm{D}$ & yes & 4000 yen? & "4000 yen" remained \\
\hline
\end{tabular}

3) Relationships between utterances and keyword movement: There was one example in which the intention expressed in the participant's utterance and the intention expressed in the movement of his keyword were different. Fragment 1 shows the example.

Fragment 1 (English translation):

01B: What Participant C said a little while ago. I think it is one of the good ideas.

02D: Is it an idea what someone eats bananas?

Participant D put "banana" in the "preparation (agreement)" box.

03B: The banana disappeared because one of us ate the banana, didn't it?

04C: Oh.

05D: So, it was a good hook.

06B: It was a good hook.

07C: It was a good hook.

Participant A put "banana" in the "preparation (agreement)" box.

They are talking about eating bananas as a comical means of realizing magic tricks where objects disappear. Member B did not put the "banana" in the box after all, even though he made a favorable and agreeing statement about magic and using bananas.
4) Questionnaire results: Table II shows the results of Question 1-1, compared to the keywords written there with the keywords in the "Agree" box (Table I), and it shows the number written in only one of them. All participants judged that all items were "concluded." The final conclusions each participant wrote in the questionnaire were roughly the same for all four; however, especially for the items of "what to do" and "preparation," there was a large difference between the keywords left by each participant in the DBS box and the questionnaire responses.

There were slight differences in the answers to the "cost" questionnaire, such as "4000 yen," "4000 yen or less," and "about 4000 yen," and it is possible to read the difference in the recognition of the participants. Regarding Question 1-2, All participants but $\mathrm{C}$ sorted the keywords into boxes at their own discretion. The average values of the answers to the three questions (four levels of answers) in Questions 1-3 were 3.25, 3.25 , and 3.5, respectively. Participants felt that the discussions were lively, the opinions tended to be the same, and the conclusions were reached smoothly. Question 2-1 showed that the results perceived by the participants themselves and the aggregated results including others were slightly different, in terms of preparation and the division of roles. In Question 2-2, Participant B wrote, "How to erase (object) with magic tricks, I answered BOX, and the others 
were cloth (answered)," while D said, “The item of division of roles, who played that role.” There was a slight discrepancy among the participants in their perceptions of the debate about what to do. It turned out that there was a discrepancy in the details. In Question 2-3, all participants looked at the keywords left by other members in the box and indicated their willingness to add or modify keywords for all four items.

\section{E. Discussion}

The DBS has the ability to display boxes for items to decide on. As a result, participants may be motivated to fill an empty box. Therefore, the next discussion (topics about empty boxes) may suddenly begin, regardless of what was being talked about immediately before. This is considered to have contributed to the fact that all items could be decided within the specified time. Later in the discussion, participants tended to speak around nouns to make them more visible in the DBS. This had the effect of preventing ambiguity about each speaker's intent. However, noun-centered remarks also had the effect of eliminating complex content and nuances, as shown by the example of the subtle variations seen in the "cost" questionnaire response.

The conclusions that each participant recognized after the discussion ended were almost the same among the participants. In other words, it can be said that the consensus was formed by the discussion, and the participants correctly recognized this. However, there were differences in the keywords that remained in each participant's box. In addition, there was one case (the example of the "banana") in which participants did not move keywords despite returning a positive response.

Some situations were observed during the discussion. When someone expressed concern about an idea, even if it was just a confirmation act, the other participants might recognize that the idea was denied and stop considering it and move on to another topic. As the banana example shows, participants always had to react positively, so that they would not take each idea out of consideration. Participants did not disagree with the other participants, even though the keywords left in the box differed from the overall conclusion. Based on these results, during the discussion process, each participant was able to freely express their personal opinions and intentions on the individual display (semi-personal space) of the DBS without fear of denying the ideas of others.

Also, in this experiment, the "opposite" box was almost non-functional. This is because it was sufficient for participants not to move the keyword to the "agreement box" if there was any objection.

\section{EXPERIMENT 2}

\section{A. Purpose}

We conducted a second experiment using DBS ver. 2.0 to show changes in participants' behaviors by displaying comments during discussions, and to try to estimate participants' intentions based on their movement of keywords.

\section{B. Method}

Participants were three males in the second year of a master's program (Participants E-G) and one male in the fourth year of the undergraduate program (Participant $\mathrm{H}$ ). They received an explanation of the experiment, signed a consent form, and then participated. Each participant was given a desktop personal computer displaying DBS ver. 2.0.

The experiment was conducted in the same room as the experiment outlined in Section 5. Participants $\mathrm{E}$ and $\mathrm{H}$ each entered a separate soundproof room, and $F$ and $G$ sat diagonally from one another across a large room. The four made voice-only calls using the Internet calling system Microsoft Teams.

The subject of the discussion was the same as in Experiment 1, but a fictitious reward was added to further motivate the participants. The content of the reward was "If the kindergarten teacher and parents voted the plan for the first place, the university will cover the cost of the gift up to 10,000 yen.” Participants acknowledged that the setting was fictitious and started the discussion. The items to be decided in the discussion were the same as the experiments in Section V.

\section{Questionnaire Survey}

After the discussion, we asked each participant to answer a questionnaire about the comments displayed on the DBS during the discussion. These comments were displayed on a separate display from the DBS, for the purpose of encouraging participants to take specific actions. At the beginning of the questionnaire, a list of comments (Comments A- F), as shown in Section IV, was provided. Not all comments were displayed to all participants, because the timing and content of comments displayed varied from participant to participant. Therefore, some participants had not seen some of the comments in the survey on the DBS.

1) Question 1: Do you think there were any comments that changed the flow of the discussion? If there were, write the symbol of the comment (A) to (F) and what kind of change it made. It doesn't matter as long as you remember.

2) Question 2: Please rate each comment $(\mathrm{A}-\mathrm{F})$. Did the comments make it easier for you to speak? We asked them to circle the applicable numbers from "Comments did not trigger speaking (1)" to “Comments triggered speaking (5).” Also, if they had any impressions of the comments, they were asked to write them in detail. If they had a comment that was not displayed, they were asked not to reply.

\section{Results}

1) Keywords left in the DBS box: In the end, a total of 73 keywords remained in the boxes of the four participants. There was almost no difference in the number of keywords among the participants. All participants had the highest number of keywords in "preparation."

Six of the remaining keywords were converted to green during the discussion. (If all participants put the same keyword in the same item box, it turned green.) There was 1 for "what to do," 3 for "preparation," and 2 for "role division." The keyword "game" turned green once, but returned to colorless at the end because Participant E removed it from his box. Regarding the cost, both “10,000 yen” (3 people) and 
"free" ( 2 people) remained, so we can see that these were not decided.

2) Questionnaire results: In Question 1, Participants F, G, and $\mathrm{H}$ answered that "Comment (A) changed the flow of discussion.” In Question 2, as well, comment (A) led the same three people as in Question 1 to be "triggered to speak." On the other hand, G replied to comment (B), "I couldn't think of how to make a statement."

Participant F had the impression that "I personally felt that it was organized," in response to the comment (C). Participant $\mathrm{H}$ replied that even if comments (D), (E), and (F) were displayed, they did not lead him to speak.

3) Behavior seen after displaying comments: Participant $\mathrm{E}$ let go of the mouse and spoke, but when Comment (F) was displayed, he put the keyword "cardboard" in the "what to do" box. This keyword was not directly related to what was being said at the time. At the same time, he deleted the keyword "drama" from the "what to do" box. Participant G also let go of the mouse and spoke, but when comment (F) was displayed, he seemed to touch the keywords in the parking area one by one with the cursor. However, he eventually started the next statement without moving any keywords. Participant $\mathrm{H}$ was laughing while listening to the other participants but not speaking, and he did not move the cursor at all. Once comment (F) appeared, he started moving the cursor and put the keyword "cardboard" in the "preparation" box.

4) Participants' opinions estimated from the movement of keywords: In this section, we extracted the utterances of each participant and the movement of keywords on the DBS to try to estimate the change in the participants' thoughts based on these actions. The subject was the keywords "game" and "VR" in the "what to do" box, and the changes in the intentions of Participants $\mathrm{E}$ and $\mathrm{F}$ for them.

The underlined part shows their utterance excerpts and indicates the display and movement of the keyword. Fragment 2 shows the reactions of other participants to Participant E's proposal "game" and "VR (virtual reality)."

Fragment 2 (English translation):

4'47”'

08E: Young children seem to like games and VR.

"Game" is displayed in the text area. F puts the keyword "game" in the parking area.

09E: You see, the teacher's son was very excited about

VR. What do you think?

"VR" is displayed in the text area. G puts "VR" in "what to

do."

10F: Oh, that might be fine. It doesn't cost much to prepare.

E puts "game" in the "what to do" box.

Participant E only put "game" in the box, but it can be inferred from his utterance that the participants were speaking in a state where the concepts of VR and game were not so distinguished. It is probable that they tried to proceed as with the ambiguous idea of whether it was VR or a game.
Participant F made a positive statement, "that might be fine," and moved only the keyword "game" into the parking area. The fact that he did not put the keyword in the box as a decision suggests that the proposal was still considered a candidate for him at that time.

Fragment 3 is an excerpt from the conversation after Participant E proposed attaching cardboard to a smartphone (VR goggles).

Fragment 3 (English translation):

7’19”

11F: I think the game might be better.

12E: Yeah.

13F: I think it's easy to imagine.

(10 seconds)

14E: There is no restriction that the event must be on stage. (5 seconds)

15G: There is only a designation to carry it out in the play room.

16E: How about bringing some candidates for the time being? H puts "game" in the "what to do" box.

17E: 26 children.

18G: That's right

G puts "game" in the "what to do" box. The word "game" in the "what to do" box turns green.

Participant F momentarily hovered his cursor over "VR" in the parking area, but did not move it to the box or put the adjacent keyword "game" in the "what to do" box.

Participant F was concerned about the "VR" in the parking area, but put only the word "game" in the box, before immediately saying, "The game may be better." From this utterance, the following two points can be inferred. $F$ thought that the "VR" plan and the "game" plan were different. At that time, the participants' conclusions tended toward "VR," but F thought that the conclusion of "games" was good.

Participants $\mathrm{H}$ and $\mathrm{G}$ also put the keyword "game" in the box, and the word "game" turned green. However, the thoughts of the other participants remained unclear, and the topic changed to a place for the show. Neither G nor $\mathrm{H}$ had given a concrete opinion on the idea of VR or the game. It is possible that F's remarks triggered them to just put the "game" in the box.

Fragment 4 is an excerpt of a conversation that begins with G's question about the content of the game.

Fragment 4 (English translation):

9'27"

19G: The rest of the tasks are what the game will be. What to do with the contents.

E puts "VR" in the "what to do" box.

14 '50"

20G: How about fetching material from YouTube? Like a roller coaster.

H puts "VR" in the "what to do" box. 
Immediately after G asked about the game, E put "VR" in the box. He may have wanted to push the VR plan in opposition to the game plan.

Fragment 5 is an excerpt of a conversation that begins with G's question about expensive preparations.

Fragment 5 (English translation):

24’22”

21G: I [can] borrow a 360-degree camera from my acquaintance's laboratory. Is there anything else (expensive)?

E removes "game" from "what to do."

(Omission)

30'09"

22E: Like a VR aquarium...

23F: That's a good idea.

F puts "aquarium” in the parking area.

(Omission)

33'13”

24G: We may place an order outside.

25E: Order?

F puts "aquarium” in "preparation."

26E: How about using Fablab?

F puts "VR" in "what to do." The term "VR" in the "what to do" box turns green.

In response to G's remark, E deleted the "game” that had been converted to green.

In the first place, $\mathrm{E}$ considered games and VR to be separate ideas. It is also thought that he was convinced that the "game" plan and the "VR" plan, whose recognition was ambiguous among the participants, proceeded to VR following the remark about G’s “360-degree camera.”

After that, F put "VR" in "what to do" and the keyword "VR" was converted to green. F agreed with E's "VR aquarium," but did not remove "game" from the box at that time. It is thought that F recognized that the VR plan was being finalized and accepted it because $G$ made a statement on the premise of the VR plan (the external order for a 360degree camera).

\section{E. Considerations}

Regarding Function 1, “designing the process," participants completed discussions on four items within the time limit, suggesting that the box is useful, as was the case of the experimental results in Section V.

Regarding Function 2, "controlling the process," Participant F put a "game" in the box and then immediately said, "A game may be better." It is thought that this encouraged the remarks of others.

By contrast, while Participants E and F tended not to hesitate to express their opinions to others, a conversation analysis suggested that G's remarks determined the flow of discussion.

It cannot be denied that the reason why $\mathrm{F}$ could not push the "game" plan to the end was that the movements of $G$ and $\mathrm{E}$ came as a result of sympathetic pressure. The movement history of keywords may be effective in guessing participants' true intentions, and by using this, it is possible to promote discussions from multiple perspectives. In addition, the flow of the discussion may have changed if the concrete examination of the game content was advanced at the initial stage of the discussion. To broaden the effectiveness of the discussion, it was considered necessary to have a mechanism for prompting other non-independent participants to think and speak concretely about each proposal.

Regarding Function 3, “organize and inspire discussions," participants answered in the questionnaire that comment (A) triggered them to review their utterances and keywords. When analyzing the behavior after the comment was displayed, there was a tendency to move the cursor and put the keyword in the box after comment (F), "It seems that you have not operated for a while," is displayed (see Fig. 5). However, some participants tried to move the cursor to do something, but did not move the keyword. Based on this, it can be said that, although the comments aroused a motivation to take action, there was not always an appropriate action to match it. The DBS generates keywords based on utterances, so even if nonspeaking participants have different opinions, there is no matching keyword.

Regarding Function 4, “form an agreement," in Experiment 1, in Section V, the common keyword was biased toward the "role division" box. However, in Experiment 2, in this section, there was a common keyword that turned green in the three boxes other than "cost." The deliverable display function that changes the color of the common keyword clearly indicates whether each item has been decided or left undecided, so it may have been effective for drawing conclusions. However, although E deleted the keyword "game," which had converted to green, and $\mathrm{G}$ and $\mathrm{H}$ also put "game" in the box, there were few remarks suggesting a game plan. Based on this, we can say that, if there is no particular objection to the keyword, it may be put in the box according to the flow of discussion, or the keyword, once put in the box, may not necessarily be in favor, due to the flow of discussion. At the beginning of the experiment, participants were asked to "put keywords that match their intentions in the box," but this instruction was not thorough enough, and it seems that the boxes were used, instead, as a record of the overall opinion. In order to realize Function 4, it may be necessary to strengthen the work of inputting the individual intentions of each participant into the DBS, instead of the overall opinion, and at the same time, to confirm the individuals' conclusions.

\section{DISCUSSION}

We experimentally examined the functions required for a system that helps participants to form a consensus and draw conclusions after giving various opinions during an online discussion.

The deliverable display function that changes the color of the common keyword clearly indicates whether each item has been decided or left undecided, so it may have been effective for drawing conclusions. However, if we do not ensure that participants put only their personal conclusions in the box, the boxes can become just notes on the discussion. 
We also discovered some concerns. It is possible that some participants will try to settle the discussion and invite other participants to move a keyword in order to turn it green. This action may promote peer pressure that is contrary to the purpose of the DBS. It can be said that the AI facilitator not only displays comments that encourage discussion, but also has a mechanism for protecting participants from peer pressure. To that end, there is a need for a mechanism that eliminates the above concerns, encourages silent participants to think independently, and links their aroused willingness to manifest their intentions to appropriate actions.

\section{CONCLUSION}

This paper proposed a discussion board system (DBS) for a future AI facilitator. The following four facilitator functions have been realized: 1) Design the process, 2) Control the field, 3) Inspire discussions, and 4) Form consensus.

Experiments with the DBS suggested the following:

1) By displaying the items to be decided, the topic can be easily changed to the next agenda item, and a conclusion can be drawn within the allotted time.

2) If the discussion participants can express their opinions and intentions on a screen that cannot be seen by others, peer pressure can be avoided to some extent.

3) The comments displayed from the system prompts users' operations on the screen. The comments triggered them to review their utterances and keywords.

4) The deliverable display function that the keyword changes to green when all participants enter the same keyword in the same box provides an opportunity to settle the discussion.

In a future effort, we aim to create a system that encourages participants to express their intentions independently by solving problems and examining the content of the comments to be displayed, and to further reduce the influence of peer pressure in the discussion.

\section{REFERENCES}

[1] H. Bang, S. L. Fuglesang, M. R. Ovesen, and D. E. Eilertsen, "Effectiveness in top management group meetings: The role of goal clarity, focused communication, and learning behavior," Scandinavian Journal of Psychology, vol. 51, no. 3, pp. 253-261, 2010.

[2] S. E. Asch, Opinions and social pressure. Scientific American, vol. 193, no. 5, pp. 31-35, W. H. Freeman and Company, California, 1955.

[3] T. Mori, Facilitator training course. Japan: Diamond, Inc., 2007. (in Japanese).

[4] S. T. Fiske, "Interpersonal stratification: Status, power, and subordination," In Handbook of social psychology, S. T. Fiske, et al., Eds., John Wiley \& Sons Inc., pp. 941-982, 2010.
[5] C. Sasaki, C. Oshima, S. Kajihara, K. Nakayama: Reaching a Final Consensus in a Discussion: the Impact of Real-time Intention Expression Related to Categories, 13th International Conference on Human System Interaction, IEEE, pp. 106-111, 2020.

[6] T. Oyama, C. Sasaki, C. Oshima, K. Nakayama: AI Facilitator Allows Participants to Conduct a Friendly Discussion and Contribute to Feasible Proposals, Communications in Computer and Information Science (CCIS) , 1420, pp.523-530, 2021.

[7] K. Watabe, S. Sakata, K. Maeno, H. Fukuoka, and T. Ohmori, "Distributed multiparty desktop conferencing system: MERMAID," Proc. of the CSCW, ACM, pp. 27-38, 1990.

[8] K. Ishitoya, S, Ohira, and K. Nagao, K. "Timemachineboard: A casual meeting system capable of reusing previous discussions," Proc. of the Fifth International Conference on Collaboration Technologies. 2009.

[9] Y. Nishihara, and W. Sunayama, "Cooperative Discussion Support System by Visualizing Participant Contribution to Discussion," Proc. of IIAI-AAI, pp. 219-224, 2015.

[10] H. Koshiba, N. Kato, and S. Kunifuji, "Effects of Negotiation MetaInformation on Group,” Proc. of KICSS 2007, pp.175-178, 2007.

[11] J. Munemori and Y. Nagasawa, "GUNGEN: groupware for a new idea generation support system," Information and Software Technology, vol. 38, no. 3, pp. 213-220, 1996.

[12] J. Han, F. Shi, and P. R. N. Childs, "The Combinator: A computer-based tool for idea generation,” Proc. of the DESIGN, pp. 639-648, 2016.

[13] K. Nishimoto, Y. Sumi, R. Kadobayashi, K. Mase, and R. Nakatsu, "Group thinking support with multiple agents," Systems and Computers in Japan, vol. 29, no. 14, pp. 21-31, 1998.

[14] H. Wang, D. Cosley, and S. R. Fussell, "Idea expander: Supporting group brainstorming with conversationally triggered visual thinking stimuli,” Proc. of the CSCW, ACM, pp. 103-106, 2010.

[15] Y. Yamaguchi, D. Shibata, C. Oshima, and K. Nakayama, "University Students Using SWISS to Display Images Searched by Keywords Extracted from Utterances,” Int. J. of IJEETDM vol. 4, no. 4, pp.131137, 2018.

[16] R. Akagawa, and T. Yuizono, "Proposal and evaluation of a real-time conference support system "INGA" by reflection of phenomenal conference,” IPSJ SIG Technical report, vol. 18, pp. 1-8, 2013. (in Japanese).

[17] S. Ohira, K. Kawanishi, and K. Nagao, "Assessing motivation and capacity to argue in a gamified seminar setting,” In Proc. of the Second International Conference on Technological Ecosystems for Enhancing Multiculturality, pp. 197-204, October 2014.

[18] K. Shimizu, K. Ogura, and K. Nishimoto, "A decision support based on the nominal group technique for facilitating review of decision making processes,” IPSJ SIG Technical Report, Vol. 2012-HCI-147, No. 8, 2012.

[19] H. Tomobe and K. Nagao, "Discussion ontology: knowledge discovery from human activities in meetings," In Annual Conference of the JSAI, pp. 33-41, Springer, Berlin, Heidelberg, June 2006.

[20] T. Ito, Y. Imi, T. Ito, and E. Hideshima, "COLLAGREE: A faciliatormediated large-scale consensus support system," Collective Intelligence 2014, pp. 10-12, 2014.

[21] T. Ito, S. Suzuki, N. Yamaguchi, T. Nishida, K. Hiraishi, and K. Yoshino, "D-Agree: Crowd Discussion Support System Based on Automated Facilitation Agent," Proc. of the AAAI Conference on Artificial Intelligence, Vol. 34, No. 09, pp. 13614-13615, 2020. 